\title{
A STUDY OF EXPRESSION OF HER2/NEU IN CARCINOMA BREAST WITH REFERENCE TO CLINICOPATHOLOGICAL FEATURES AND PROGNOSTIC INDEX
}

\author{
Jeena Josephin J. $R^{1}$, Suresh Babu $K^{2}$ \\ ${ }^{1}$ Assistant Professor, Department of Surgery, Kilpauk Medical College. \\ ${ }^{2}$ Assistant Professor, Department of Surgery, Kilpauk Medical College.
}

\begin{abstract}
\section{BACKGROUND}

Carcinoma of breast has clinical heterogeneity with high morbidity and mortality. Determination of prognostic factors is important in improving the overall survival in breast cancer patients. HER2/neu is one of the powerful predictors of poor prognosis. Thus, a study of HER2/neu expression estimated by immunohistochemistry in breast cancer is the need of the hour. This study investigates correlations between the presence of HER2/neu and various clinicopathological prognostic parameters in primary breast carcinomas.

1. Study of the HER2/neu status in breast carcinomas in the study sample.

2. To find the association of HER2/neu status with clinicopathological prognostic parameters in breast carcinomas in the study sample.

3. To find the association of HER2/neu status with lymph node status.
\end{abstract}

\section{MATERIALS AND METHODS}

Patients diagnosed as carcinoma breast, admitted in Department of General Surgery in our institution and post-operative modified radical mastectomy specimens were examined for gross and microscopic features. Immunohistochemistry was used to study the HER2/neu expression. HER2/neu status was correlated with various clinicopathological prognostic parameters.

\section{RESULTS}

There was a significant statistical association between HER2/neu expression with lymph node involvement $(\mathrm{p}=0.012)$ and presenting symptoms such as pain and nipple discharge. Expression of HER2/neu expression was increased in tumour size of more than $2 \mathrm{cms}(64 \%)$ and higher tumour grade (90\%). The major histological subtype was infiltrating duct carcinoma, NOS type. Meanwhile, there was no significant association of HER2/neu expression with menopausal status, NPI groups and other histological parameters.

\section{CONCLUSION}

Our study data indicates that HER2/neu may be a more powerful predictor for poor prognosis as its expression is associated with important prognostic parameters like increased tumour size, high tumour grade, high NPI score and lymph node involvement.

\section{KEYWORDS}

Immunohistochemistry; HER2/neu; Breast Carcinoma; Clinicopathological Prognostic Parameters; Nottingham modification of Scarff-Bloom-Richardson grading (NSBR grading); Nottingham Prognostic Index.

HOW TO CITE THIS ARTICLE: Josephin JJR, Babu SK. A study of expression of HER2/neu in carcinoma breast with reference to clinicopathological features and prognostic index. J. Evolution Med. Dent. Sci. 2016;5(90):6726-6732, D0I: $10.14260 /$ jemds/2016/1520

\section{BACKGROUND}

Breast carcinoma is the most common malignant tumour. It is the leading cause of death due to carcinoma in women. It has an incidence of more than one million cases reported from all over the world. ${ }^{1}$ It is of serious concern owing to the rising incidence of the disease, both in the developed and developing countries. $^{2}$ In India breast cancer was the second to lung carcinoma in its incidence in women prior to 1990, but now it occupies the top rank among cancers in women in India owing to the gradual change in lifestyle of Indian women. ${ }^{3}$

Financial or Other, Competing Interest: None.

Submission 26-09-2016, Peer Review 28-10-2016,

Acceptance 03-11-2016, Published 10-11-2016.

Corresponding Author:

Dr. Jeena Josephin J. R,

Kalluthinnavilai,

Kirathur Post,

Kanyakumari-629181, Tamilnadu.

E-mail: drjeena10@gmail.com

DOI: $10.14260 /$ jemds $/ 2016 / 1520$
In India most of the patients present with palpable cancer and even with lymph node metastasis at the time of their first visit. 4

Breast cancer is not a single disease, but it is a disease with multiple distinct biological subtypes and varied natural history. It has a wide spectrum of clinical, pathological and molecular features which alter prognosis and management. Over the last few decades, there have been outstanding advances in breast cancer management resulting in drastic decrease in mortality and decreased morbidity for women living with disease. 5

Stratification of patients after taking into consideration various prognostic parameters has assumed a great therapeutic importance. ${ }^{1}$ Histopathological examination of the primary carcinoma and the axillary lymph nodes is a major prognostic indicator. Many prognostic and predictive factors have been identified by the College of American Pathologists to guide the clinical management of women with breast cancer. The prognostic factors includes invasive carcinoma or in-situ disease, distant metastases, lymph node metastases, tumour size, locally advanced disease, histologic grade, 
histologic subtype, inflammatory carcinoma and hormonal receptor status and increased expression of HER2/neu. ${ }^{6}$

In the current management guidelines, Oestrogen Receptor (ER), Progesterone Receptor (PR) status and overexpression of HER2/neu are the three most useful predictive factors for response to specific therapeutic agents. ${ }^{4}$

HER2/neu, otherwise known as neu or c-^rbB-2, is the product of an oncogene. Its amplification and overexpression varies from $11 \%$ to $32 \%$ of breast carcinomas. ${ }^{7}$ Today, Immunohistochemistry (IHC) is the centre stage in the demonstration of newer monoclonal antibodies. ${ }^{8}$ IHC is used commonly for evaluating HER2/neu protein expression in breast cancer. HER2/neu expression is an independent prognostic factor in patients with both node-positive and node-negative breast cancer.

HER2/neu has greater prognostic value than most currently used prognostic factors including ER-PR status. ${ }^{9}$ HER2/neu positive cancers exhibit resistance to tamoxifen, but not to aromatase inhibitors or ovarian ablation. ${ }^{10}$

The presence of HER2/neu is related to a high-grade tumour and poor prognosis, but favourable response to monoclonal antibody therapy and disease survival. ${ }^{11}$ Therefore, there is a growing clinical demand for analysis of the HER2/neu status of current and archived breast cancer specimens. $^{12}$

\section{Objectives of the Study -}

1. Study of the HER2/neu status in breast carcinomas in the study sample.

2. To find the association of HER2/neu status with clinicopathological prognostic parameters in breast carcinomas in the study sample.

3. To find the association of HER2/neu status with lymph node status.

\section{MATERIALS AND METHODS}

Patients diagnosed as carcinoma breast, admitted in Department of General Surgery in our Institution during the period from November 2014 to August 2015 were studied.

Clinical data were obtained from patient's history, clinical examination, imaging, FNAC, biopsy and hospital records. The specimens were sent to the Pathology Department. The tumours were typed according to the WHO classification system. The Nottingham modification of Bloom Richardson grading system was used for grading.

Each case was assessed considering important clinicopathological prognostic parameters like size of the tumour, histological grade, presence of necrosis, lymphovascular invasion, involvement of surgical margins, fibrosis, stromal reaction, involvement of the skin in the form of nipple and areola/Pagetoid spread and metastases in the axillary lymph nodes. The Nottingham Prognostic Index (NPI) was calculated. After calculation of the NPI score, all the 50 cases of carcinoma breast were divided into six prognostic groups. All the 50 cases were subjected to IHC study for HER2/neu. The polymer based IHC kit of BioGenex RTU was used. A score of $2+$ and 3+ HER2/neu were considered positive for immunostaining.

Correlation of HER2/neu expression with abovementioned important clinicopathological prognostic parameters and with NPI was done. The collected data was entered in Excel sheet and analysed using Epi Info software and the descriptive statistics, Chi-square test, Student's t-test,
McNemar's test and other applicable statistical tests were applied for the data as applicable. The $p$ value of $<0.05$ was considered statistically significant. Cases are selected by following inclusion and exclusion criteria.

\section{Inclusion Criteria}

All the cases admitted with carcinoma breast in our institution.

\section{Exclusion Criteria}

Patients with recurrence in carcinoma breast.

\section{OBSERVATION AND RESULTS}

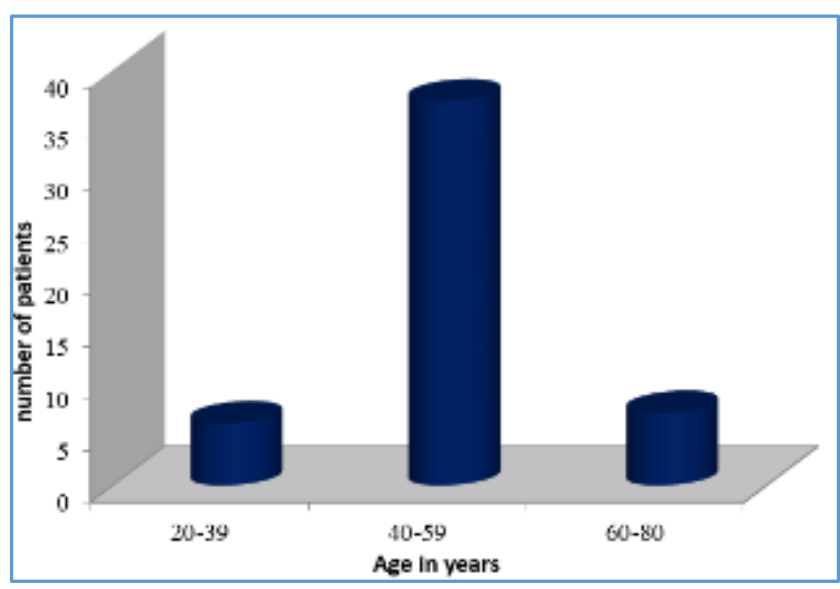

Figure 1. Age Distribution of Patients with Carcinoma Breast

In the present study, the age of the patients with carcinoma breast ranged from 20 to 80 years. Majority of the patients $(70 \%)$ were in the age group of 40 to 59 years.

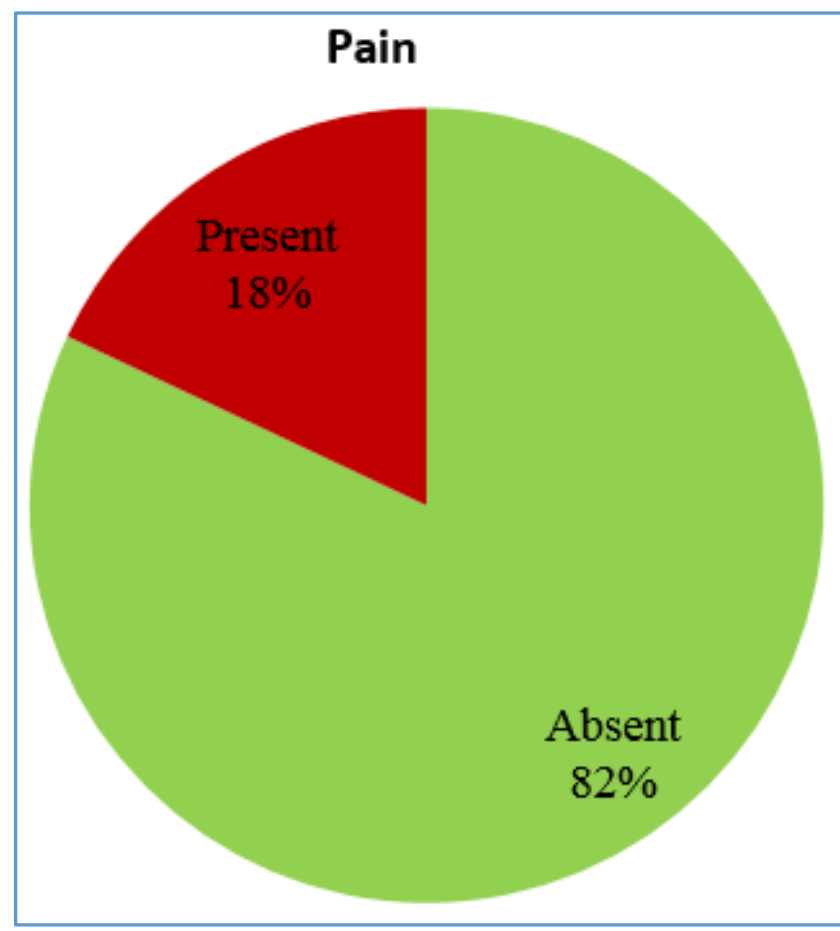

Figure 2. Pain in Patients with Carcinoma Breast

All the $50(100 \%)$ cases were presented with lump in the breast and $9(18 \%)$ cases with pain in addition to lump. 


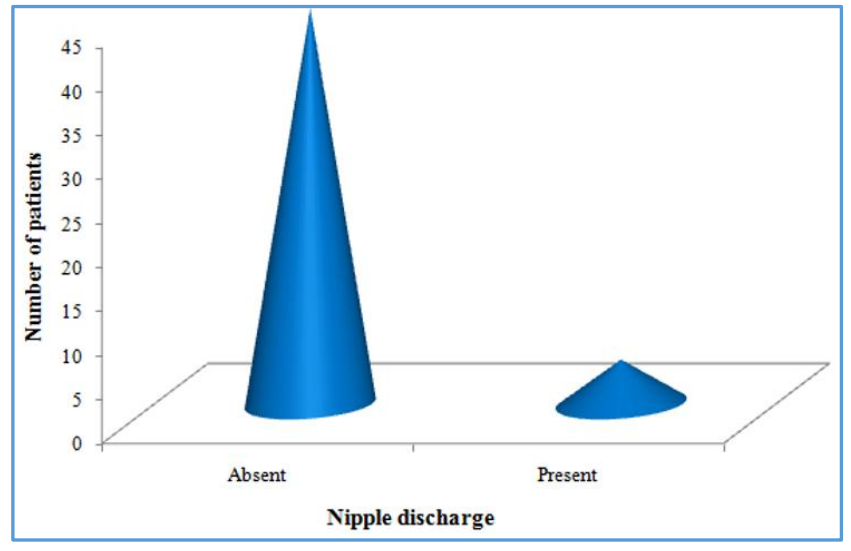

Figure 3. Nipple Discharge in

Patients with Carcinoma Breast

In our study, 5 cases presented with nipple discharge.

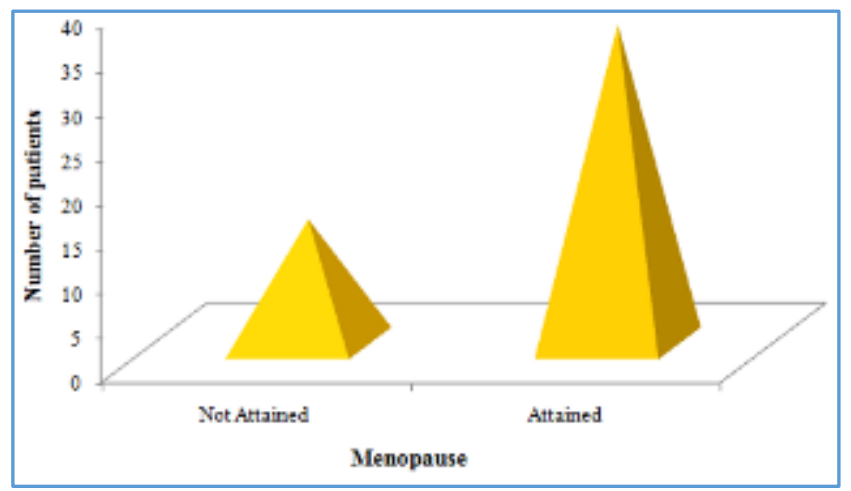

Figure 4. Menopausal Status of

Patients with Carcinoma Breast

In the present study, $72 \%$ patients were in the postmenopausal age group.

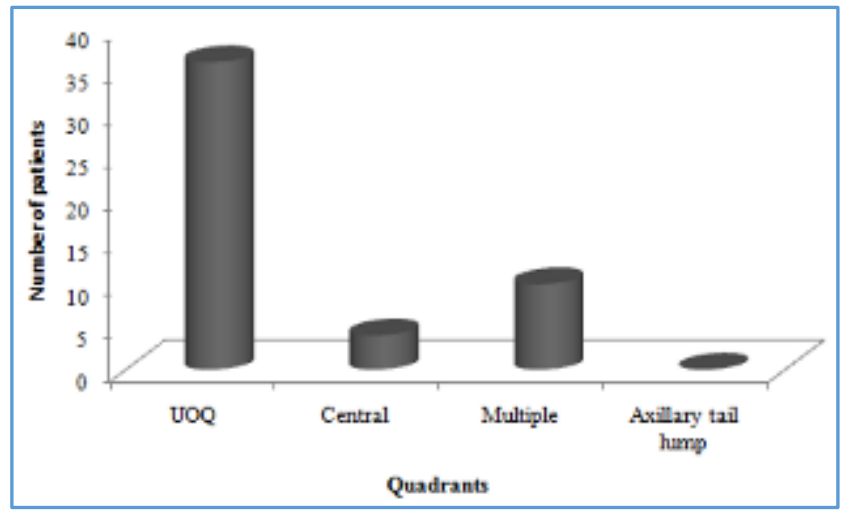

Figure 5. Distribution of Carcinoma Breast according to Location of the Tumour

On clinical examination, the tumour was in the upper outer quadrant in $72 \%$ of cases. In $8 \%$ cases, the tumour was central in location and in $20 \%$ of cases the tumour was involving multiple quadrants.

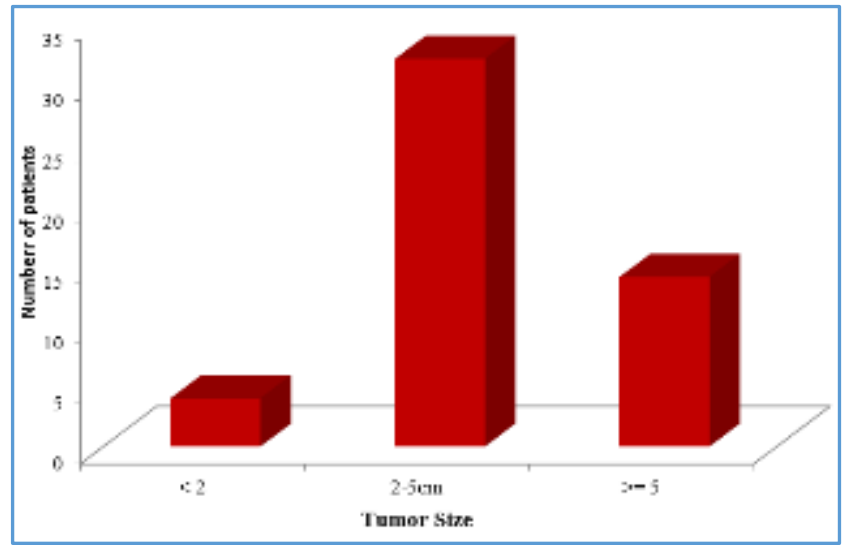

Figure 6. Distribution of Carcinoma Breast according to Size of the Tumour

In the present study, the size of the tumour ranged from $1.5 \mathrm{cms}$ to $8 \mathrm{cms}$. In 4 cases the tumour size was $<2 \mathrm{cms}$, in 32 cases the tumour size ranged from 2 to $5 \mathrm{cms}$ and 14 cases had a tumour size of $>5 \mathrm{cms}$.

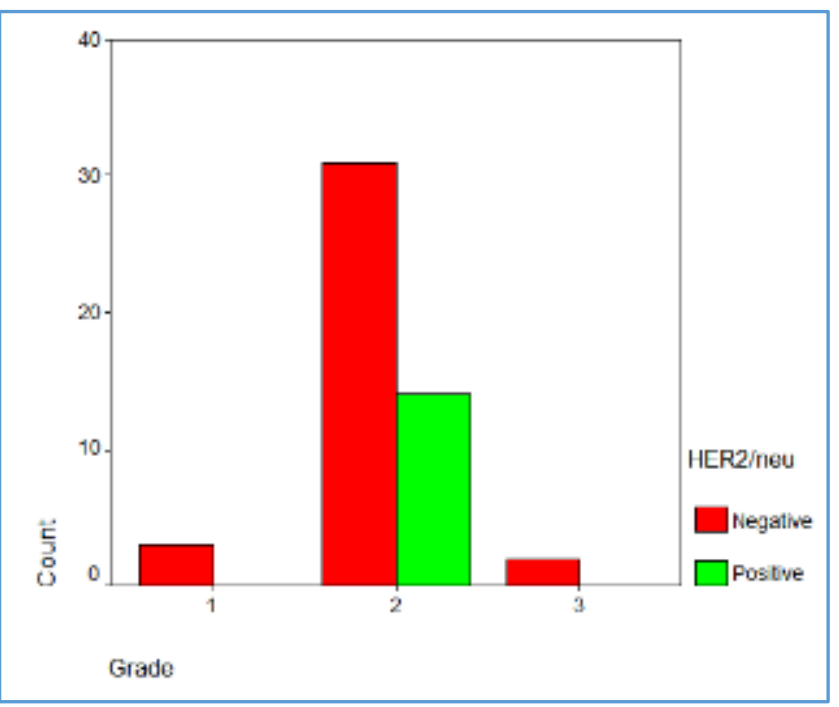

Figure 7. Histological Grading of the Cases using NSBR System

Of the 50 cases studied, majority of cases (90\%) were of Grade 2.

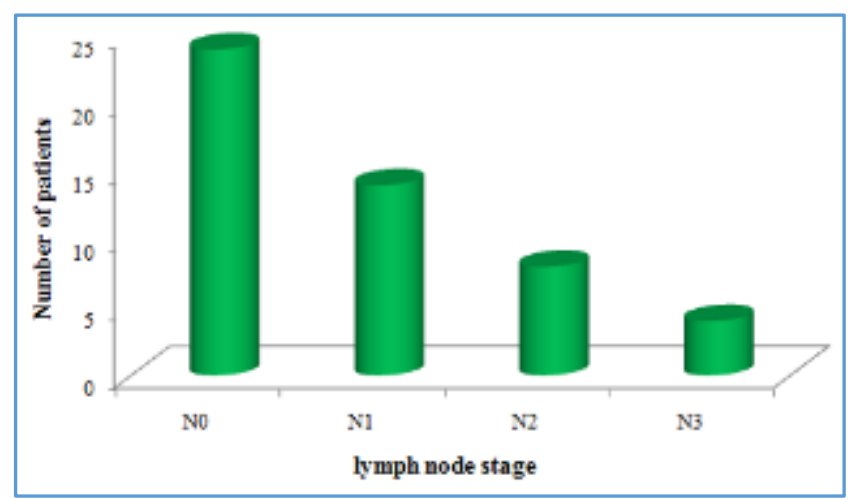

Figure 8. Staging of Lymph Nodes in Carcinoma Breast

Of the 50 cases, 24 cases were in stage N0 followed by 14 cases in stage N1, 8 cases in stage N2 and 4 cases in stage N3. 


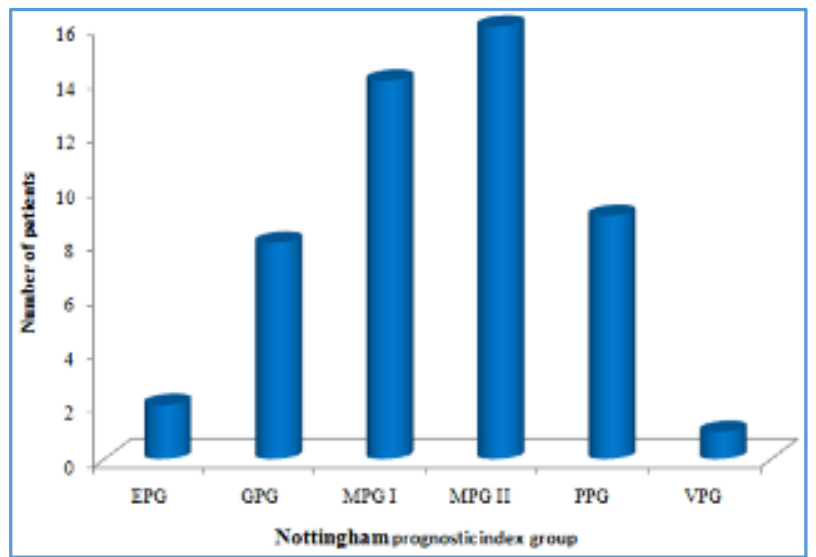

Figure 9. Distribution of Carcinoma Breast according to NPI

In our study, the NPI showed $32 \%$ of cases in MPG II followed by $28 \%$ of cases in MPG I.

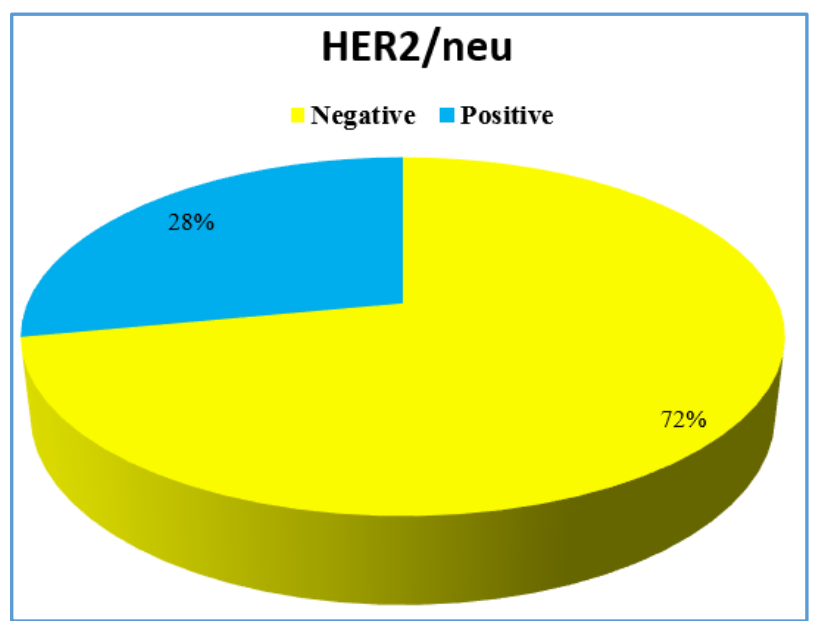

Figure 10. Her2/Neu Expression of the Tumour

In the present study, the Her2/neu was expressed only in 14 out of 50 cases of carcinoma breast.

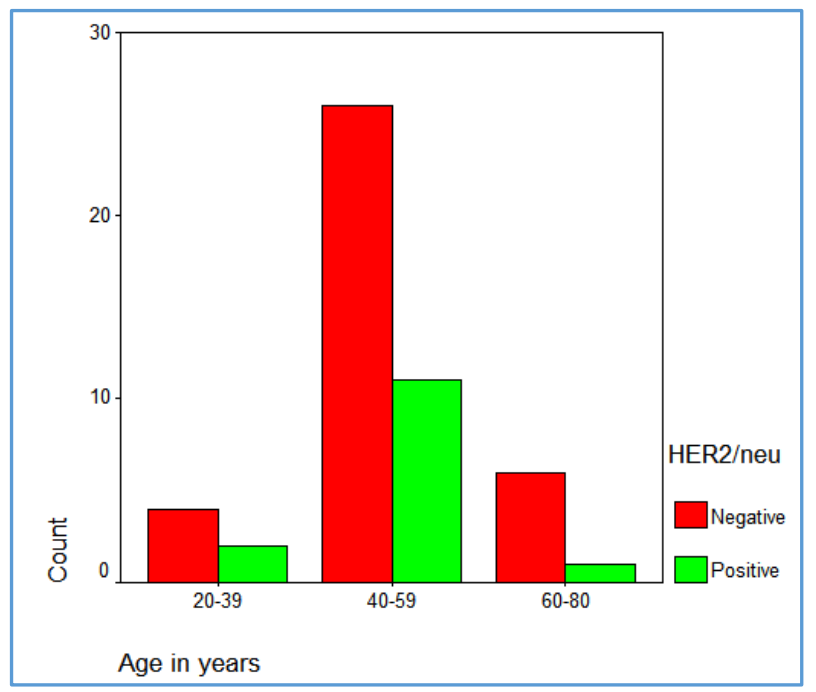

Figure 11. Age Distribution of Carcinoma Breast and its Association with Her2/Neu

Of the 50 cases, maximum HER2/neu positivity was seen in the age group of $40-59$ years $(78.6 \%)$ and the least HER2/neu positivity was seen between the age group of 60 -
80 years (7.1\%). A statistically significant association of HER2 $/$ neu with age was not noted ( $\mathrm{p}$ value $=0.673$ ) .

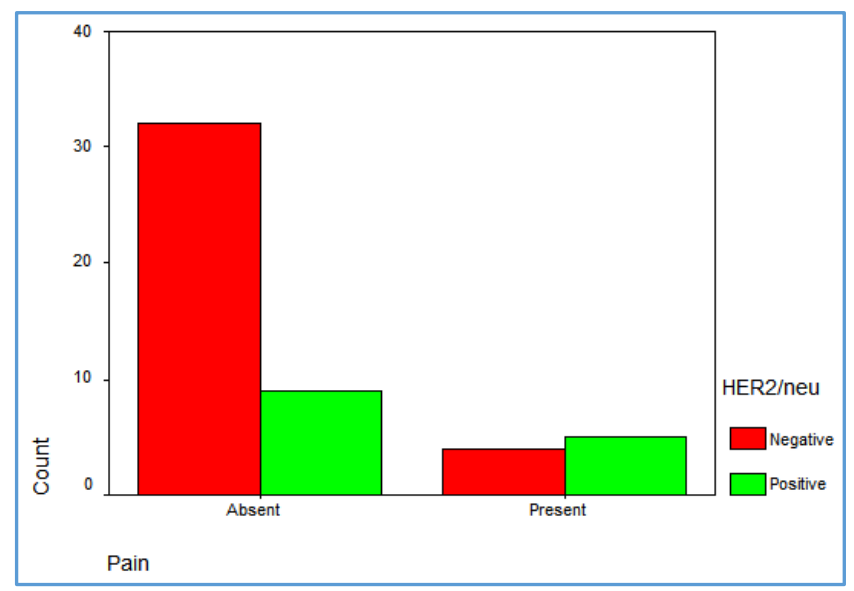

Figure 12. Pain in Patients with Carcinoma Breast and its Association with Her2/Neu

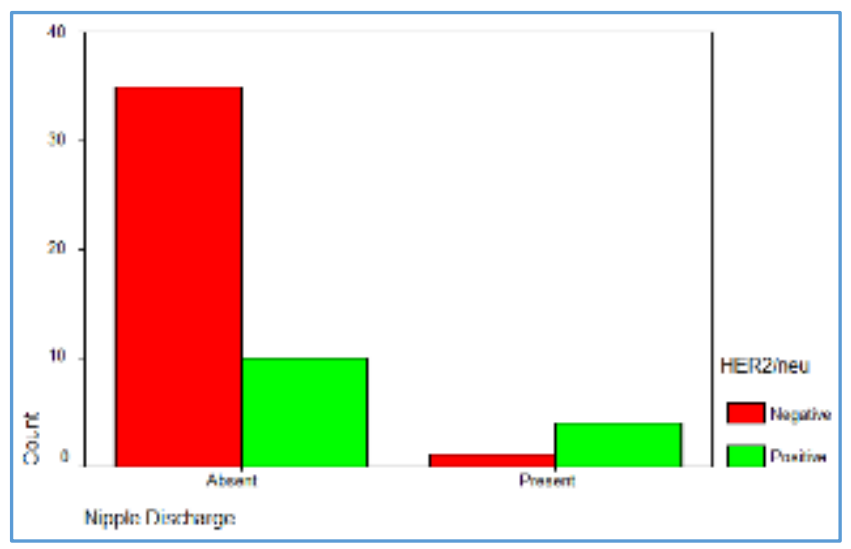

Figure 13. Nipple Discharge in Patients with Carcinoma Breast and its Association with Her2/Neu

In our study, a statistically significant association of HER2/neu with pain and nipple discharge was noted in the present study with $\mathrm{p}$ value 0.042 and 0.006 respectively.

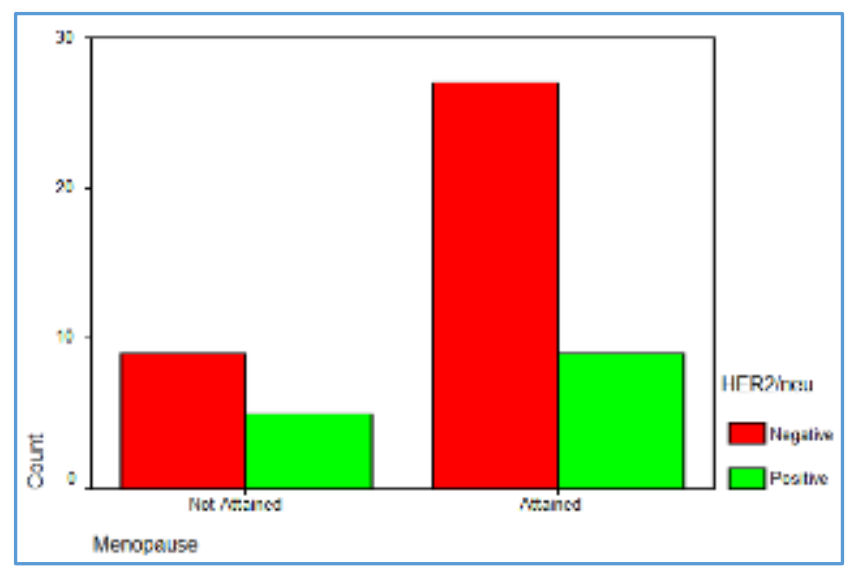

Figure 14. Menopausal Status of Carcinoma Breast and its Association with Her2/Neu

Maximum HER2/neu positivity (64.3\%) was seen in the postmenopausal age group. No statistically significant association of HER2/neu with menopausal status was noted in the present study ( $\mathrm{p}$ value $=0.449$ ). 


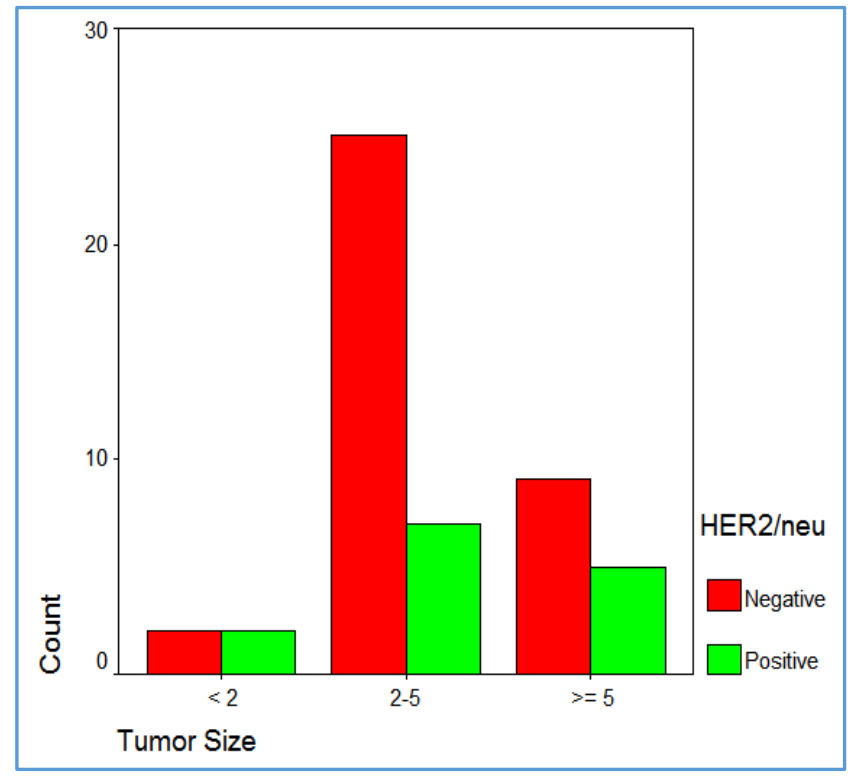

Figure 15. Size of the Tumour and its Association with $\mathrm{Her} 2 / \mathrm{Neu}$

The maximum HER2/neu positivity was seen in 7 (50\%) with the tumour size between $2-5 \mathrm{cms}$. HER2/neu was positive in $5(35.7 \%)$ out of 14 cases with the tumour size $>5$ cms. No statistically significant association of HER2/neu with tumour size was noted in the present study ( $p$ value $=0.374$ ).

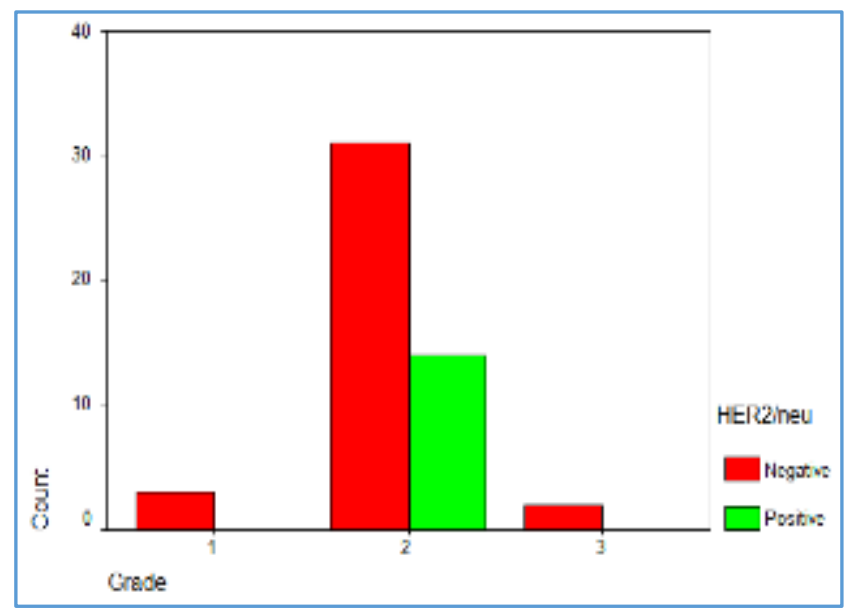

Figure 16. Histological Grading of Tumour using NSBR System and its Association with Her2/Neu

In our study while correlating the over-expression of HER2/neu with the histological grading, all cases of HER2/neu positivity were seen only in Grade 2 . No statistically significant association of HER2/neu with histologic grade was noted in the present study ( $\mathrm{p}$ value $=0.340)$.

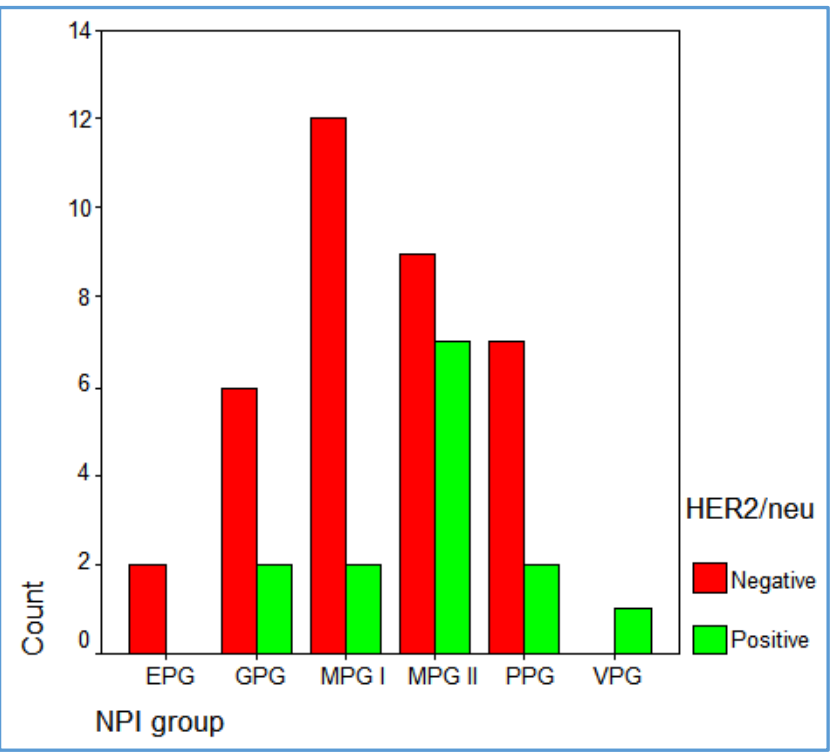

Figure 17. Nottingham Prognostic Index (NPI) and its Correlation with $\mathrm{Her} / \mathrm{Neu}$

In the present study, majority of HER2/neu positivity was seen in MPG II. No statistically significant association of $\mathrm{HER} 2 /$ neu with NPI was noted ( $\mathrm{p}$ value $=0.235$ ).

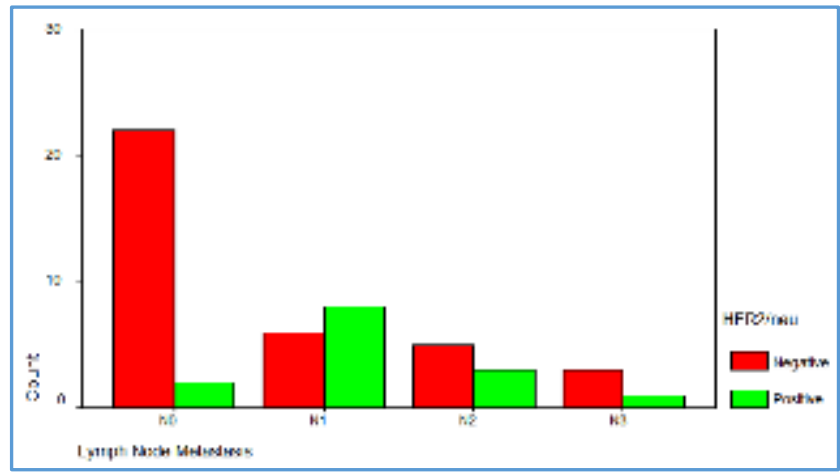

\section{Figure 18. Lymph Node Staging and its Correlation with Her2/Neu}

Out of 50 cases of carcinoma breast, 26 cases (52\%) showed lymph node metastases with 14 (28\%), 8 (16\%) and 4 $(8 \%)$ cases in stage N1, N2 and N3 respectively. HER2/neu was positive in $8(57.1 \%), 3(37.5 \%)$ and $1(25 \%)$ cases of stage N1, $\mathrm{N} 2$ and N3 respectively. Statistically significant association of HER2/neu with the presence of lymph nodes was noted ( $p$ value $=0.012$ )

\section{DISCUSSION}

In our study of 50 cases of breast carcinoma, majority of the patients were between the age group of 40 - 59 years. This finding is similar to studies of Mansour Al-Moundhri et al13 (49.6 years), Azizun-Nisa et al14 (48.3 years), MoradiMarjaneh $\mathrm{M}$ et al ${ }^{15}$ (47.4 years) and Lobna Ayadi et al ${ }^{16}$ (51.5 years).

In the present study majority of the cases (64\%) had the tumour size ranging from $2-5 \mathrm{cms}$ followed by 14 (28\%) cases of tumour size of $>5 \mathrm{cms}$. In the study by Azizun-Nisa et al ${ }^{14}$ also, $52.7 \%$ of tumour were between $2-5 \mathrm{cms}$ and $35.3 \%$ were $>5 \mathrm{cms}$. The study of Mona M. Rashed et al ${ }^{17}$ also $54 \%$ of cases had tumour size of $2-5 \mathrm{cms}$, while $36 \%$ had a tumour size of > $5 \mathrm{cms}$. 
Among the 50 cases of invasive carcinoma breast in our study, majority of the cases (49 cases, 98\%) were of infiltrating ductal carcinoma, NOS type and 1 case $(2 \%)$ was invasive papillary carcinoma. Similarly, in the study by Farid Saleh et al ${ }^{18}$ the most common histologic subtype was infiltrating ductal carcinoma, NOS type (98\%) and $2 \%$ of invasive papillary carcinoma.

Of the 50 cases of invasive carcinoma breast studied, majority of the cases ( 45 cases, $90 \%$ ) were of Grade 2 and the least number of cases (4\%) were of Grade 3. Similar findings were noted in the studies of Mona Rashed et al ${ }^{17}$ (2007), Saleh $\mathrm{F}$ et $\mathrm{al}^{18}$ (2007), Azizun-Nisa et $\mathrm{al}^{14}$ (2008) and Moradi M et al ${ }^{15}$ (2008) were majority in Grade 2.

The HER2/neu was expressed in 14 (28\%) out of 50 cases of carcinoma breast in the present study. The HER2/neu expression in various studies varied from $15 \%$ to $93.4 \%$.

The results in our study showed that Her2/neu expression increased with age. A study by Al-Moundhri et al ${ }^{13}$ (2003) also showed similar results where 12 out of 13 patients with positivity for HER2/neu were $>40$ years of age. However, many other studies showed increased HER2/neu expression in younger age group (Almasri et al [2005], Farid Saleh et al 18 [2007] and Moses Ambroise et $\mathrm{al}^{3}$ [2011]). Studies by H. J. Huang et $\mathrm{al}^{19}$ (2005), Mona Rashed et al17 (2007) and Vaidyanathan K. K. et al20 (2010) showed no correlation of HER2/neu expression with age.

Patients in post-menopausal age group showed more HER2/neu positivity (64.3\%) than pre-menopausal age group patients $(35.7 \%)$. No statistically significant association of HER2/neu with menopausal status was noted in the present study ( $\mathrm{p}$ value $=0.449$ ). Similarly, studies by Rashed $\mathrm{M}$ et al ${ }^{17}$ (2007) and Vaidyanathan K. K. et al20 (2010) showed no statistically significant correlation of HER2/neu expression with menopausal status.

Survival analysis done by Vaidyanathan K. K. et al ${ }^{20}$ (2010) revealed that HER2/neu overexpression is poor prognostic indicator. At 40 months of followup $83.8 \%$ of HER2/neu negative individuals had disease free survival, whereas only $46.1 \%$ of HER2/neu positive individuals had disease free survival.

Tumour size is one of the most useful predictors of behaviour of breast carcinoma. In the present study, while correlating the HER2/neu positivity with the size of the tumour, majority was seen in with the tumour size between 2 - $5 \mathrm{cms}(50 \%)$ followed by $35.7 \%$. HER $2 /$ neu positivity was seen with the tumour size $>5 \mathrm{cms}$. However, no statistically significant association of HER2/neu with tumour size was noted in the present study ( $\mathrm{p}$ value $=0.374$ ).

While correlating the overexpression of HER2/neu with the histologic subtype, all the 14 positive cases of HER2/neu was seen in infiltrating ductal carcinoma, NOS type. None of the other types showed HER-2 positivity. Similarly, $90.9 \%$ and $71.7 \%$ of infiltrating duct carcinoma (NOS type) were positive for HER2/neu in the studies done by Naeem et al (2008) ${ }^{21}$ and Saleh F et al ${ }^{18}$ (2007).

While correlating the overexpression of HER2/neu with the histological grading, all the HER2/neu positive tumours were Grade 2 tumours. This suggests that the percentage of expression of HER2/neu is more frequent in higher grade breast carcinomas than in lower grade. The studies by various authors also showed similar results. No statistically significant association of HER2/neu with histologic grade was noted in the present study ( $\mathrm{p}$ value $=0.102$ ) similar to the studies by
Naeem et al (2008) and Resit Dogan et al (2011). Unlike our study, most of the studies by Lovekin et al ${ }^{22}$ (1991), Mona Rashed et al ${ }^{17}$ (2007), Saleh et al ${ }^{18}$ (2007), Tatjana IvkovicKapical et $\mathrm{al}^{23}$ (2007), Moradi M. M. et al ${ }^{15}$ (2007) and AzizunNisa et al ${ }^{14}$ (2008) showed statistically significant association of HER2/neu with histologic grade.

The correlation of HER2/neu with NPI in the 50 cases of carcinoma breast showed that most of the HER2/neu positive cases were seen in the moderate prognostic Group II (50\%). None of the cases in excellent group were positive for HER2/neu. No statistically significant association of HER2/neu with NPI was noted in the present study ( $\mathrm{p}$ value = $0.235)$.

The Nottingham Prognostic Index (NPI) is a wellestablished and widely used method of predicting survival of operable primary breast cancer. No studies correlating the NPI with HER2/neu status with best of our knowledge has been done so far. Further studies have to be done to determine the significance of correlation of HER2/neu with NPI and to find if this correlation has an advantage over NPI alone in predicting the survival rate of breast carcinoma patients.

Of the 14 HER2/neu positive cases in primary tumour of our study, 12 cases showed metastases in the lymph nodes and only 2 cases showed no metastases in the lymph nodes suggesting that HER2/neu positivity increases the risk of metastases. Statistically significant association of HER2/neu with lymph node involvement was noted in the present study ( $p$ value $=0.012)$. In the studies by Tatjana et $\mathrm{al}^{23}$ (2007), Moradi M. M. et al15 (2007), Azizun-Nisa et al ${ }^{14}$ (2008) and Naeem M. et al (2008) also showed increased expression of HER2/neu in cases with lymph node involvement and only study Azizun-Nisa et al ${ }^{14}$ (2008) had a statistically significant correlation.

\section{CONCLUSION}

- $\quad$ Majority of the cases were in the age group 40 - 59 years $(70 \%)$

- $\quad$ Majority of cases had a tumour size of 2 to $5 \mathrm{cms}(64 \%)$.

- Majority of the cases (98\%) were of infiltrating ductal carcinoma NOS type and $2 \%$ of invasive papillary carcinoma.

- $\quad$ Majority of cases (90\%) were of NSBR Grade 2.

- Majority of the cases (52\%) showed axillary lymph node metastases.

- Majority of the cases were in the MPG II (32\%) group.

- A statistically significant association of HER2/neu with lymph node involvement was noted in the present study ( $\mathrm{p}$ value $=0.012$ )

- No statistically significant association of HER2/neu with menopausal status was noted in the present study $(\mathrm{p}$ value $=0.449$ ).

- No statistically significant association of HER2/neu with tumour size was noted in the present study ( $\mathrm{p}$ value $=$ 0.374). However, the percentage of the HER2/neu expression was more in tumour size of $>2 \mathrm{cms}$.

- $\quad$ HER2/neu expression was seen only in infiltrating duct carcinoma, NOS type and no statistically significant association of HER2/neu with the histologic subtype was noted in the present study.

- No statistically significant association of HER2/neu with histologic grade was noted in the present study ( $\mathrm{p}$ value $=$ 0.340). However, the percentage of the HER2/neu expression was more in higher grade tumours. 
- No statistically significant association of HER2/neu with NPI group was noted in the present study ( $\mathrm{p}$ value = 0.235 )

HER2/neu overexpression participates in the pathogenesis of breast carcinomas. They are indicators of poor prognosis in breast carcinoma and usually correlated with histological grade and stage components of breast carcinomas.

Our study evaluated HER2/neu positive immunoreactivity and correlated with established prognostic factors like clinicopathological parameters, NSBR grade and NPI in 50 cases of carcinoma breast.

According to the data of our study, a significant statistical association was found between HER2/neu and presenting symptoms such as pain and nipple discharge and lymph node status.

Although, no significant statistical association of HER2/neu with tumour size and grade was seen, HER2/neu expression was more frequent in cases with tumour size more than $2 \mathrm{cms}$ and higher grades. This perhaps is attributed to the study of limited number of cases.

No statistical correlation of HER2/neu with menopausal status and NPI group was noted. HER2/neu positive immunoreactivity was more frequently seen in infiltrating duct carcinoma, NOS type.

In conclusion, our study indicates that HER2/neu may be a more powerful predictor for poor prognosis, as its expression is associated with important prognostic parameters like increased tumour size, high tumour grade, high NPI score and lymph node involvement.

In future it is necessary to carry out studies with large samples of carcinoma breast and using other molecular prognostic markers to evaluate the prognosis and to provide better therapeutic options.

\section{REFERENCES}

1. Rosai J. Breast. Rosai and Ackerman surgical pathology. $9^{\text {th }}$ edn. Missouri: Elsevier 2004:1763-1827.

2. Tavassoli FA, Devilee P. WHO classification of tumourspathology and genetics tumours of the breast and female genital organs. Lyon: International agency for research on cancer (IARC press) 2003.

3. Ambroise M, Ghosh M, Mallikarjuna VS, et al. Immunohistochemical profile of breast cancer patients at a tertiary care hospital in south India. Asian Pacific J Cancer Prev 2011;12(3):625-9.

4. Lester SC. The Breast. In: Kumar V, Abbas AK, Fausto N. eds. Robbins and Cotran Pathologic Basis of Disease. 8th edn. Philadelphia: Elsevier 2010:1073-90.

5. Guidelines for management of breast cancer/by WHO Regional Office for the Eastern Mediterranean: EMRO Technical Publications Series, 31. 2006.

6. Bradley KT. Prognostic and predictive markers in breast carcinoma. CAP Cancer Committee 2007.

7. Almasri NM, Hamad MA. Immunohistochemical evaluation of human epidermal growth factor receptor 2 and estrogen and progesterone receptors in breast carcinoma in Jordan. Breast Cancer Research 2005;7(5): 598-604.

8. Jambhekar NA, Chaturvedi AC, Madur BP. Immunohistochemistry in surgical pathology practice: a current perspective of simple, powerful, yet complex tool. IJPM 2008;51(1):2-11.
9. Slamon DJ, Clark GM, Wong SG, et al. Human breast cancer: correlation of relapse and survival with amplification of the HER2/neu oncogene. Science 1987;235(4785):177-82.

10. James R, Thriveni $K$, Krishnamoorty L, et al. Clinical outcome of adjuvant endocrine treatment according to Her2/neu status in breast cancer. Indian Journal of Medical Research 2011;133(1):70-5.

11. Wolff AC, Elizabeth $M$, Hammond $H$, et al. American society of clinical oncology/college of American pathologists guideline recommendations for human epidermal growth factor receptor 2 testing in breast cancer. Archives of Pathology \& Laboratory Medicine 2007;131(1):18-43.

12. Jacobs TW, Gown AM, Yaziji H, et al. Her2/neu protein expression in breast cancer evaluated by immunohistochemistry. a study of interlaboratory agreement. Am J Clin Pathol 2000;113(2):251-8.

13. Al-Moundhri $\mathrm{M}$, Nirmala $\mathrm{V}$, Al-Mawaly $\mathrm{K}$, et al. Significance of p53, Bcl-2 and HER2/neu protein expression in omani arab females with breast cancer. Pathology Oncology Research 2003;9(4):226-31.

14. Nisa A, Bhurgri $Y$, Raza F, et al. Comparison of ER, $P R$ and HER/2/neu (C-erb B 2) reactivity pattern with histologic grade, tumor size and lymph node status in breast cancer. Asian J Cancer Prevention 2008;9(4):553-6.

15. Moradi-Marjaneh M, Homaei-Shandiz F, Shamsian SAA, et al. Correlation of HER2/neu over expression, p53 protein accumulation and steroid receptor status with tumor characteristics: an iranian study of breast cancer patients. Iranian J Publ Health 2008;37(3):19-28.

16. Ayadi L, Khabir A, Amouri H, et al. Correlation of HER-2 over-expression with clinico-pathological parameters in Tunisian breast carcinoma. World Journal of Surgical Oncology 2008;6:112.

17. Rashed MM, Ragab NM, Galal MK. The association of Her2/neu over-expression in relation to p53 nuclear accumulation, hormonal recceptor status and common clinico-pathological prognostic parameters in a series of Egyptian women with invasive ductal carcinoma. Eur J Gen Med 2007;4(2):73-79.

18. Saleh F, Abdeen S. Pathobiological features of breast tumours in the State of Kuwait: a comprehensive analysis. Journal of Carcinogenesis 2007;6:12.

19. Huang HJ, Neven P, Drijkoningen $M$, et al. Association between tumour characteristics and Her2/neu by immunohistochemistry in 1362 women with primary operable breast cancer. J Clin Pathol 2005;58(6):611-6.

20. Vaidyanathan K, Kumar P, Reddy CO, et al. ErbB-2 expression and its association with other biological parameters of breast cancer among Indian women. Indian Journal of Cancer 2010;47(1):8-15.

21. Naeem M, Nasir A, Aman Z, et al. Frequency of Her2/neureceptor positivity and its association with other features of breast cancer. J Ayub Med Coll Abbottabad 2008;20(3):23-6.

22. Lovekin C, Ellis IO, Locker A, et al. c-erbB-2 oncoprotein expression in primary and advanced breast cancer. $\mathrm{Br} \mathrm{J}$ Cancer 1991;63(3):439-43.

23. Ivkovic-Kapical T, Knezevic-Usaj S, Djilas-Ivanovic D, et al. Correlation of Her2/neu protein overexpression with other prognostic and predictive factors in invasive ductal breast cancer. In Vivo 2007;21(4):673-8. 